\title{
Effect of Heat Input on the Mechanical Behaviour of Al-Cu FSW Lap Joints
}

\author{
Aldoni Gabriel Wiedenhoft ${ }^{1}$, Heraldo José de Amorim², Tonilson de Souza Rosendo ${ }^{3}$, \\ Marco Antonio Durlo Tier * (D), Afonso Reguly ${ }^{4}$ \\ ${ }^{1}$ Universidade Federal do Pampa - Unipampa, Campus Alegrete, Alegrete, RS, Brasil \\ ${ }^{2}$ Departamento de Engenharia Mecânica - DEMEC, Universidade Federal do Rio Grande do Sul - \\ UFRGS, Porto Alegre, RS, Brasil \\ ${ }^{3}$ Programa de Pós-Graduação em Engenharia - PPEng, Universidade Federal do Pampa - Unipampa, \\ Alegrete, RS, Brasil \\ ${ }^{4}$ Laboratório de Metalurgia Física, Programa de Pós-Graduação em Engenharia de Minas, \\ Metalurgia e de Materiais - PPGE3M, Universidade Federal do Rio Grande do Sul - UFRGS, \\ Porto Alegre, RS, Brasil
}

Received: November 02, 2017; Revised: March 29, 2018; Accepted: April 16, 2018

\begin{abstract}
Dissimilar Al-Cu joints are desirable due to the combination of the good electrical and thermal properties of copper with the economic advantages of aluminium. However, different chemical, mechanical and thermal properties turn dissimilar welding into a challenge with traditional fusion welding techniques. Friction stir welding appears to be a good alternative to welding dissimilar materials. Most of the works in Al-Cu FSW have been performed with Al on top. This work investigates the influence of heat input on the shear strength of aluminium-copper lap joints produced by FSW with a copper over aluminium lap configuration. Welds produced with the $\omega / \mathrm{v}$ rate of $200 \mathrm{rev} . \mathrm{mm}^{-1}$ or 500 rev. $\mathrm{mm}^{-1}$ resulted in the melting of the base materials and material leaking. Joints with shear tensile strength varying from 76 to $85 \%$ of the original resistance of AA6060 T5 were produced when the $\omega / v$ rate was varied from 80 to 110 rev. $\mathrm{mm}^{-1}$. The fracture was governed by tension overload on the aluminium sheet, resulting in little influence of welding defects, such as tunnelling, on the joint strength.
\end{abstract}

Keywords: Friction stir welding - FSW, dissimilar welding, shear strength, Al-Cu lap joints.

\section{Introduction}

Joining dissimilar materials is considered a priority in welding technology ${ }^{1}$. However, the welding of dissimilar material by conventional welding processes is limited due to the differences between the properties of materials, including melting temperatures, which can lead to internal discontinuities, solidification defects and the formation of brittle intermetallic compounds that can compromise the welded joint.

In the case of aluminium-copper joints, the differences in the physical and chemical properties of these materials make their joining by fusion welding techniques difficult or even impractical. For instance, Mai and Spowage ${ }^{2}$ observed solidification cracks at the centre of copper-aluminium joints; yet, Rao et al. ${ }^{3}$ described poor corrosion resistance for TIG welded aluminium-copper alloys due to the formation of the $\mathrm{AlCu}_{2}$ intermetallic compound, which forms galvanic cells with the aluminium matrix, causing impairment of the latter.

Friction stir welding (FSW) has been studied as an alternative to joining aluminium and copper. Some benefits of this technique compared to fusion welding are higher strength, absence of defects associated with the solidification such as cracks, porosity and segregation, improved corrosion strength and reduced occurrences of heat associated problems such as distortion and the formation of intermetallic compounds.

The FSW process parameters involve joint type and materials, tool geometry, tool rotational speed $(\omega)$, welding speed $(v)$ and tool tilt angle. Xue et al. ${ }^{4,5}$ reported that $\omega$ is the main responsible for the heat input and, therefore, it is considered by many researchers to be the most important process parameter for the FSW.

Ericsson and Sandstrom ${ }^{6}$ after studied the influence of welding speed on the fatigue of friction stir welds concluded that welding speed is also important and is related to heat distribution over the joint. Therefore, Vilaça et al. ${ }^{7}$ used the ratio $\omega / \nu$ to classify the FSW process as hot, intermediary or cold.

Bisadi et al. ${ }^{8}$ used the ratio $\omega / v^{2}$ to calculate the heat input and concluded that very low welding temperatures lead to defects like channels in the interface sheets. It was also observed that the sheet thinning, caused by the shoulder, the hooking defect and the brittle intermetallic compounds are the main reasons for fracture. 
Ouyang et al. ${ }^{9}$ and Carlone et al. ${ }^{10}$ described that the chemical affinity of aluminium and copper can lead to the formation of intermetallic phases such as $\mathrm{CuAl}_{2}, \mathrm{CuAl}$, $\mathrm{Al}_{3} \mathrm{Cu}_{4}$ and $\mathrm{Cu}_{9} \mathrm{Al}_{4}$, whose effects can be deleterious, and Bisadi $^{8}$ concluded that the amount of intermetallic compounds formed in the stir zone increases with temperature.

Akbari et al. ${ }^{11}$ reported that the material position is an important parameter that affects the quality of the Al-Cu weld. They reported that the plate position affects the heat input and concluded that the maximum fracture load is obtained with $\mathrm{Al}$ on top of $\mathrm{Cu}$. Furthermore, Galvão et al. ${ }^{12}$ reported the influence of tool geometry in the formation and distribution of intermetallic phases.

Although important results have been reached on $\mathrm{Al}-\mathrm{Cu}$ joining by FSW, extensive work on this subject is still required, since the most efforts so far have been on butt joints rather than on lap joints. It is still necessary to investigate a large number of Al-Cu couples, test different weld configurations, evaluate the process on thicker plates, estimate the influence of process parameters on the surface finishing and the effect of weld defects on the mechanical properties of the joints.

Moreover, lap joints with copper positioned over aluminium with high industrial applicability, such as the 6xxx series, have not been extensively reported, and this is the purpose of the present work. Since the chemical affinity of aluminum and copper can lead to the formation of intermetallic phases, whose effects can be deleterious ${ }^{9,13,14}$, this work investigates the heat input influence in keeping the formation of defects and intermetallic phases to a minimum.

\section{Materials and Methods}

The FSW joints were processed in overlap configuration from ASTM 6060 T5 aluminium and ASTM B110 half hard copper bars. Table 1 presents the mechanical properties of these materials.

Copper was positioned over aluminium due to its higher melting point. The length of the weld seams was $20 \mathrm{~mm}$, since for the main applications of Al-Cu joints, as electrical connector, this size is expected to be satisfactory.

Fig. 1a illustrates the joint geometry for samples used in shear tests and fig. $1 \mathrm{~b}$ presents the tool geometry and dimensions. The pin was $4.5 \mathrm{~mm}$ in length.

During welding, the axial force was measured with a $10 \mathrm{kN}$ load cell. For temperature acquisition, eight PT-100 sensors were mounted on a holder designed to provide the necessary stiffness and to allow the angular displacement of the tool $\left(3^{\circ}\right)$.

Table 1. Mechanical properties of tested materials
The temperature sensors were positioned at the side of the weld samples, as shown in fig. 1a, that is, $9.5 \mathrm{~mm}$ from the weld seam centre. Although the measured values do not correspond to real temperatures in the weld seam, they are suitable to compare the average temperature distribution for the different welding parameters.

The process parameters were based on data from the literature as published by Mehta and Badheka ${ }^{15}$, and refined by means of preliminary tests to provide a range of parameters where visually defect free welds were produced. The $\omega / v$ rate was used to classify the heat input as cold, hot or intermediate according to Vilaça et al. ${ }^{7}$.

Table 2 presents the process parameters. Four samples were produced for each welding design (WD); three were used for shear tensile testing and one for microstructural and microhardness assessment.

The shear tensile tests were carried out in an MTS 810 universal testing machine with a crosshead speed of $1 \mathrm{~mm} . \mathrm{min}^{-1}$.

Microhardness was performed to evaluate the microstructural changes of the base materials. The joints were sectioned in a transversal direction in two positions: at the initial section (IS) and at the final section (FS) of the weld seam. Two profiles consisting of values measured with $0.5 \mathrm{~mm}$ intervals were performed for each WD, positioned at the centre of each plate.

The specimens were obtained for metallographic assessment by cross sectioning the welded joints, which were ground and polished according to standard procedures and chemically etched with a solution containing identical quantities of $\mathrm{H}_{2} \mathrm{O}, \mathrm{NH}_{4} \mathrm{OH}$ and $\mathrm{H}_{2} \mathrm{O}_{2}$ for etching the copper part and with a $0.5 \%$ hydrofluoric acid solution for the aluminium plate.

\section{Results and Discussion}

\subsection{Surface morphology}

Preliminary tests allowed establishing a processing window where welds with defect free surface may be produced.

For a $v=10 \mathrm{~mm} \cdot \mathrm{min}^{-1}$, only tool rotational speeds ranging from 800 to $1100 \mathrm{rpm}$ led to visually sound joints. According to heat input analysis, these WD are classified as intermediate (table 2). Out of this range, process parameters led to low strength welds, as is the case for Cold Welds (Fig. 2a) or Hot Welds (Fig. 2b,c). In both cases distortion is observed.

In some cases, the melting of base materials or even material leaking occurred as for the sample 5000/10 (Fig. 2c).

\begin{tabular}{lcccc}
\hline Material & Yield strength (MPa) & $\begin{array}{c}\text { Ultimate tensile strength } \\
(\mathrm{MPa})\end{array}$ & Elongation (\%) & \multicolumn{2}{c}{ Brinell hardness } \\
& & $1 \mathrm{HB})$ & 66 \\
\hline ASTM 6060T5 aluminium & 110 & 3150 & 8 & $60-373$ \\
ASTM B110 copper (half hard) & $265-333$ & $6-12$ & 905 \\
\hline
\end{tabular}




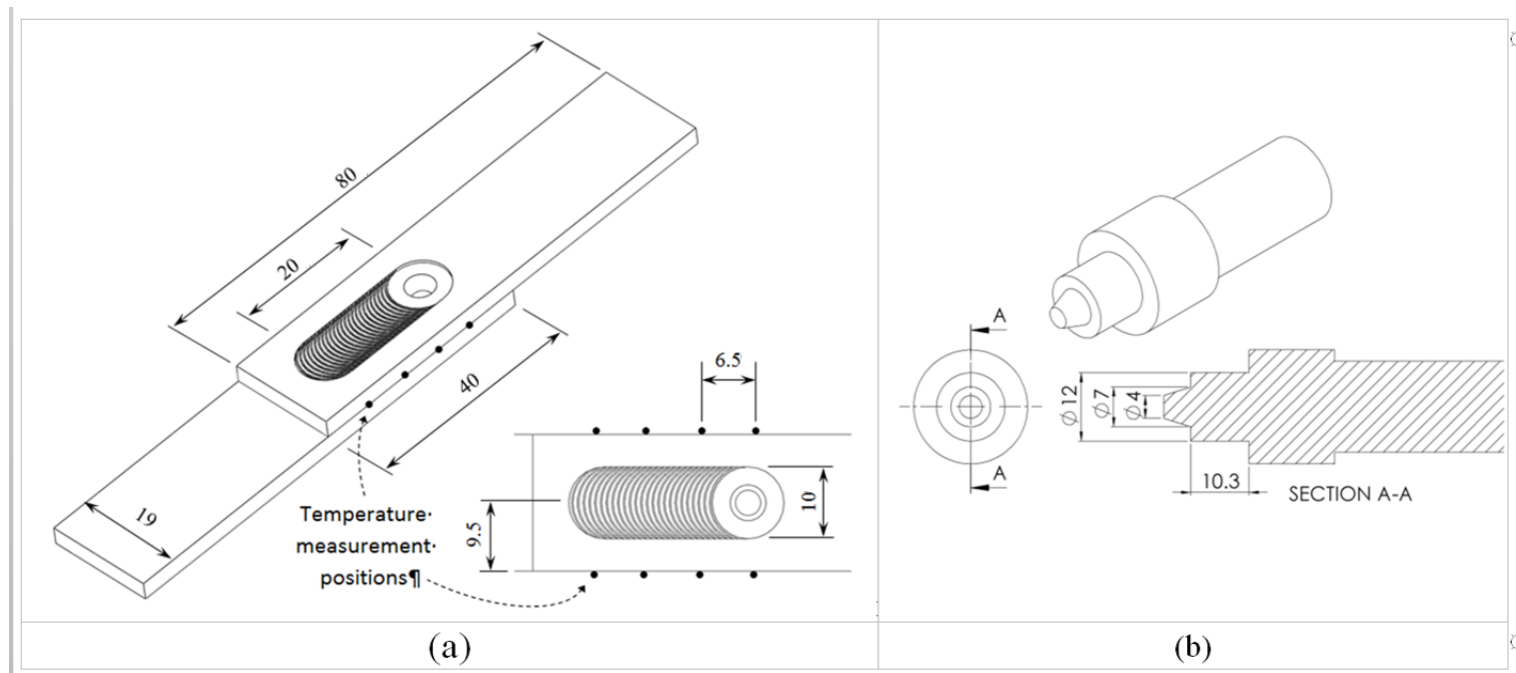

Figure 1. Welded samples (a) and tool geometry and dimensions (b).

Table 2. Process Parameters

\begin{tabular}{lcccc}
\hline $\begin{array}{l}\text { Welding } \\
\text { Design WD }\end{array}$ & $\begin{array}{c}\omega \\
(\mathrm{rpm})\end{array}$ & $\begin{array}{c}v \\
\left(\mathrm{~mm} \cdot \mathrm{min}^{-1}\right)\end{array}$ & $\begin{array}{c}\omega / v \\
\left(\mathrm{rev} \cdot \mathrm{mm}^{-1}\right)\end{array}$ & $\begin{array}{c}\text { Heat Input } \\
\text { Classification }\end{array}$ \\
\hline $800 / 30$ & 800 & 30 & 26.7 & Cold \\
$800 / 10$ & 800 & 10 & 80 & Intermediate \\
$900 / 10$ & 900 & 10 & 90 & Intermediate \\
$1000 / 10$ & 1000 & 10 & 100 & Intermediate \\
$1100 / 10$ & 1100 & 10 & 110 & Intermediate \\
$2000 / 10$ & 2000 & 10 & 200 & Hot \\
$5000 / 10$ & 5000 & 10 & 500 & Hot \\
\hline
\end{tabular}

$\omega=$ tool rpm; $v=$ welding speed; plunge depth $=4.5 \mathrm{~mm}$; plate thickness $=3.25 \mathrm{~mm}$

Fig. 2 d corresponds to WD 1000/10 (Intermediate Welding), where no apparent flaws were found.

Fig. 3 presents an optical micrograph obtained from one of the leaked spots indicated in Fig. 2c. The microstructure of this region shows aluminium dendrites, indicating excess heating and partial fusion during welding.

These results may be explained by the analysis of the heat input on FSW. Schneider et al. ${ }^{16}$, when studying the interfacial contact condition in FSSW, and Liechty and Webb $^{17}$, when modelling the frictional boundary condition in FSW, proposed two types of contact condition: sticking or slipping interfacial contact conditions.

Assuming the same contact condition, the main variable to affect the heat input is the tool rotational speed as stated by Gerlich et al. ${ }^{18}$. Furthermore, Tier et al. ${ }^{19}$ concluded that the time of the process is relevant to heat input which is associated, in the present case, with welding speed. Rodrigues et al. ${ }^{20}$ showed that energy increases almost linearly in relation to $\omega / v$.

Therefore, a low heat input, as shown in Fig. $2 \mathrm{a}(\omega / \mathrm{v}$ $=26.7$ rev. $\mathrm{mm}^{-1}$ ), was insufficient to allow adequate metallurgical mixing of the materials. On other hand, when the heat generated is too high, as shown in Fig. $2 \mathrm{~b}(\omega / \nu=200$ rev. $\mathrm{mm}^{-1}$ ), the viscosity of material was very low and even material leaking occurred, as shown in fig. $2 \mathrm{c}(\omega / v=500$ rev. $\left.\mathrm{mm}^{-1}\right)$. For intermediate heat input, no surface defects were observed (fig. 2d). These results indicate the need of a proper definition of the $\omega / v$ relation. For the materials and setup used in this investigations a $\omega / v$ between 80 and 110 rev. $\mathrm{mm}^{-1}$ led to sound joints.

\subsection{Axial force and temperature}

Fig. 4 presents the axial force measured during the welding process. Since the resistance of the materials to the penetration of the tool is dependent upon the temperature, higher axial forces are expected at the initial stages of the process when the welding tool plunges into base material, as observed in Fig. 4 a.

Welds produced at smaller rotational speeds are expected to show higher axial force, since less heat is generated. The maximum axial force values, which indicate a linear and inverse relation between rotational speed and the maximum axial force with a correlation of $97.4 \%$, are plotted in fig. $4 \mathrm{~b}$.

Fig. $4 \mathrm{c}$ indicates the existence of two different levels for the average axial force: a higher, from 5.5 to $6.0 \mathrm{kN}$, associated with rotational speeds of 800 and $900 \mathrm{rpm}$ and a lower, slightly above $2.0 \mathrm{kN}$, for rotational speeds of 1000 and $1100 \mathrm{rpm}$. This feature may be explained by the contact condition theory as described by Schneider et al. ${ }^{16}$.

According to the contact condition theory, as tool rotational speed increases, the viscosity of material around the tool is reduced, and, therefore, a decrease in the axial forces is expected. As a consequence, the material around the tool reduces its heat generation, allowing the recovery of its strength. Fig. 5 present the values for maximum and average temperatures measured at eight different points along the welding, as shown in fig. 1 . 

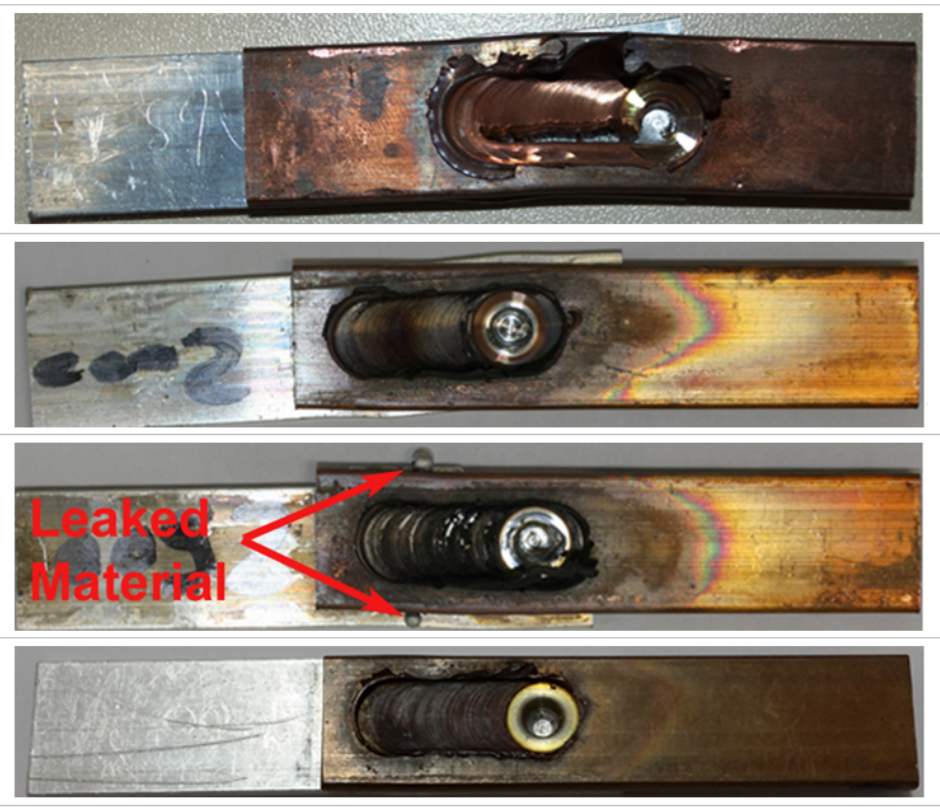
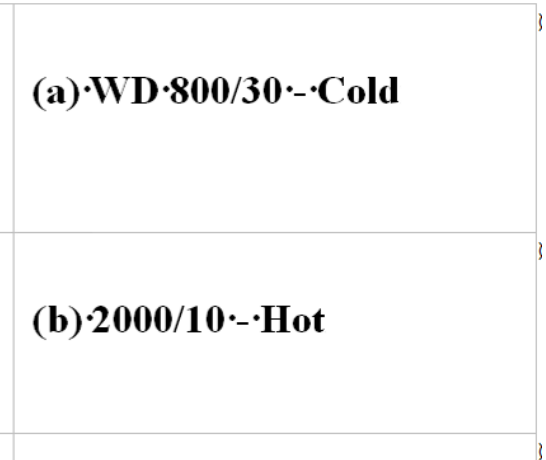

(c) $\cdot \mathbf{5 0 0 0} / \mathbf{1 0} \cdot \cdot \cdot \mathbf{H o t}$

\section{(d) $\cdot 1000 / 10 \cdot-\cdot$ Intermediate}

Figure 2. Visual inspection of welds produced with different rotational speeds and welding speed.

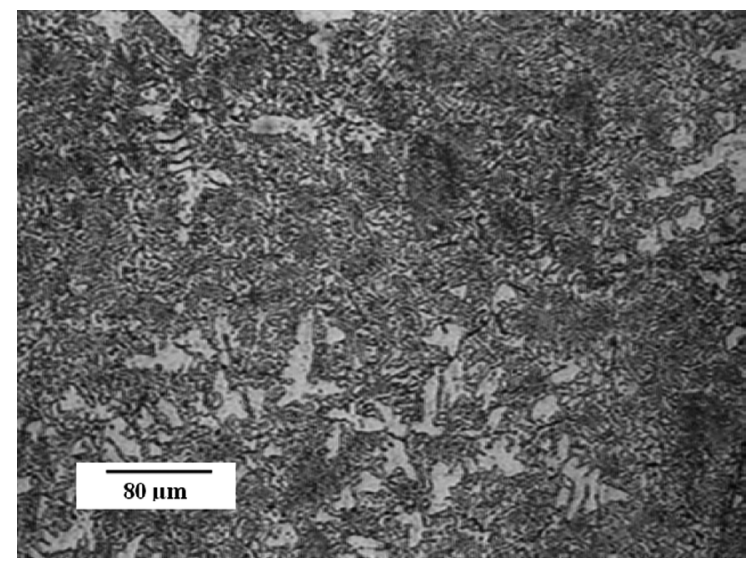

Figure 3. Micrograph of leaked material from Fig. 2c showing the presence of aluminium dendrites.

Data analysis show higher temperatures associated with higher rotational speeds. This result is expected, since the heat input is directly affected by the rotational speed during FSW, as has been described by Shen et al. ${ }^{21}$.

Since the temperature sensors were positioned at 9.5 $\mathrm{mm}$ from the welding line, and thus $4.5 \mathrm{~mm}$ from the tool shoulder, they do not represent the real temperatures in the weld, which are expected to be much higher. However, they give an important insight concerning the energy input for the different WD. Gerlich et al. ${ }^{18}$ reported that the calculated strain rate in FSSW of AA7075-T6 decreases considerably when tool rotational speed increases from 1000 to $3000 \mathrm{rpm}$, resulting in tool slippage due to a temperature increase in the weld region.

\subsection{Shear tensile tests}

Shear strength of the welds is presented in Fig. 6. Joints produced with $1100 \mathrm{rpm}$ presented the highest dispersion of shear tensile strength, indicating a less stable result. Probable causes for this dispersion are related to the higher temperatures caused by the higher heat input, which may be affecting the contact condition, causing slippage of the tool.

Variance analysis (ANOVA) with a 0.05 confidence interval indicates no significant influence of the tool rotational speed on the strength of welded joints. This result is in consonance with the work of Rodrigues et al. ${ }^{20}$ which indicates a small influence of tool rotational speed when the window of stability is reached.

An $85 \%$ joint efficiency $(\eta)$ of Al was reached which can be considered satisfactory since the majority of the research for $\mathrm{Al}-\mathrm{Cu}$ joints reaches values approximately $75 \%$. For instance, Tan et al. ${ }^{22}$ found a joint efficiency of $75,6 \%$ for a joint of $5 \mathrm{~A} 02$ aluminium alloy-pure copper; Bisadi et al. ${ }^{8}$ reached $75 \%$ for joint of AA5083 aluminium alloy-pure copper and Muthu and Jayabalan ${ }^{23}$ found 70,6\% for joints of AA1100-H14-pure copper; on the other hand, Avettand-Fenoel ${ }^{24}$ obtained only 49\% for joint AA 6082-pure copper, while Kahl and Osikowicz ${ }^{25}$ showed that tensile strengths of the joints exceeded the tensile strengths of the base materials for AA6063-T6 and soft annealed DHP copper. However, in the latter research the joints were submitted to cold rolling after friction stir welding.

\subsection{Microhardness}

To investigate the effect of temperature in weld zones, two microhardness profiles were measured in the cross section, one in the beginning (IS - Initial Section) and the other in 


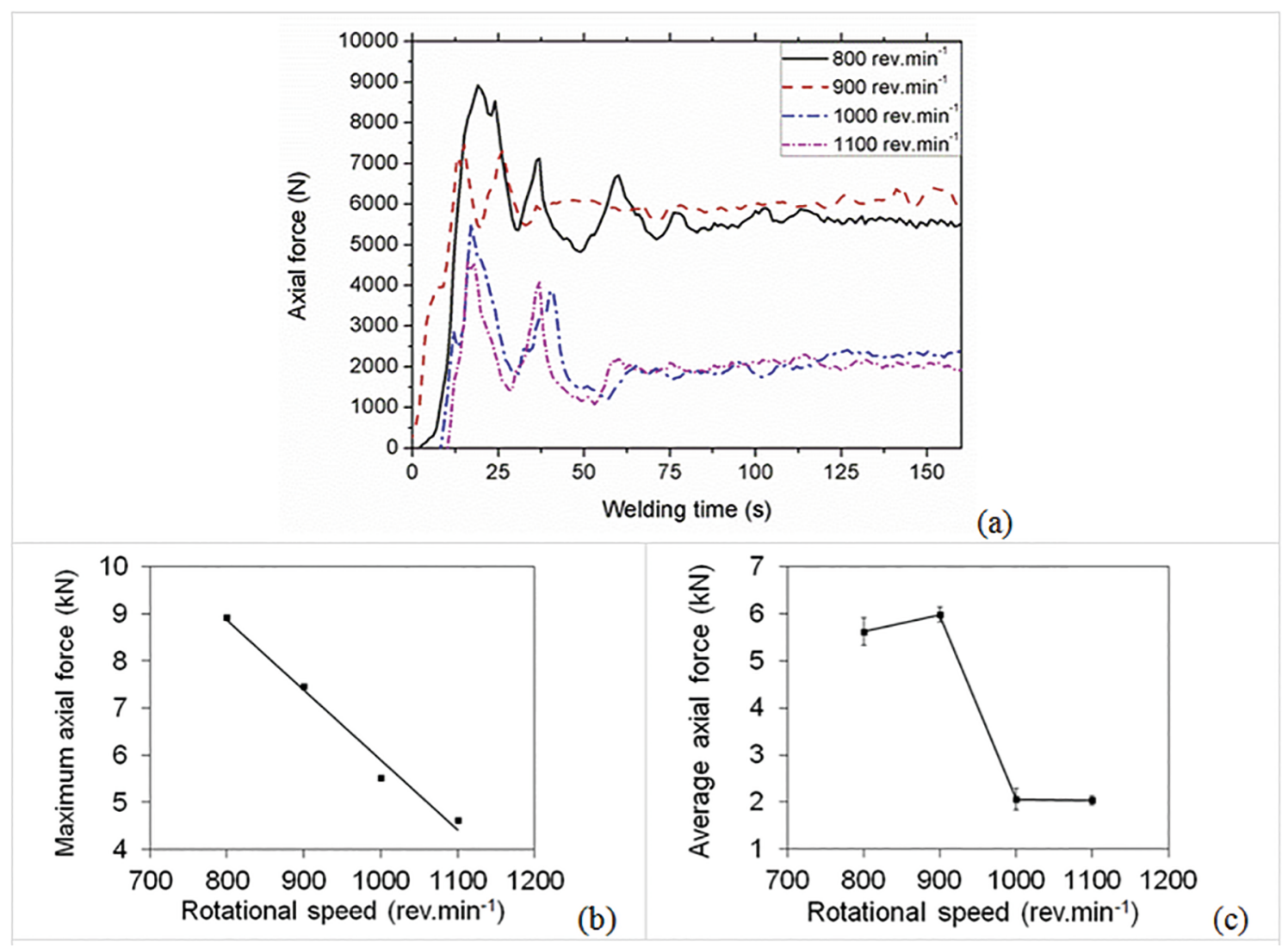

Figure 4. (a) axial force during welding; (b) maximum axial force values registered for each tested condition; and (c) average axial force for the different rotational speeds.

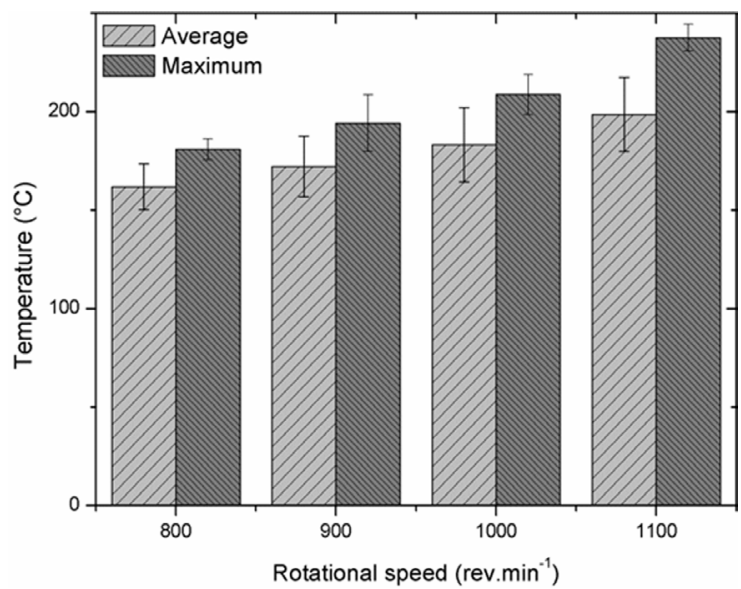

Figure 5. Temperature measured for the different tested conditions: maximum registered peaks and peak averages obtained from the eight sensors.

the end (FS - Final Section) of the weld seam. Fig. 7 presents the microhardness profiles for WD 800/10. The horizontal lines indicate the hardness of the base material for both $\mathrm{Al}$ and $\mathrm{Cu}$. It is possible to see a hardness increase at the centre of the weld seam, especially in the part associated with the aluminium sheet.

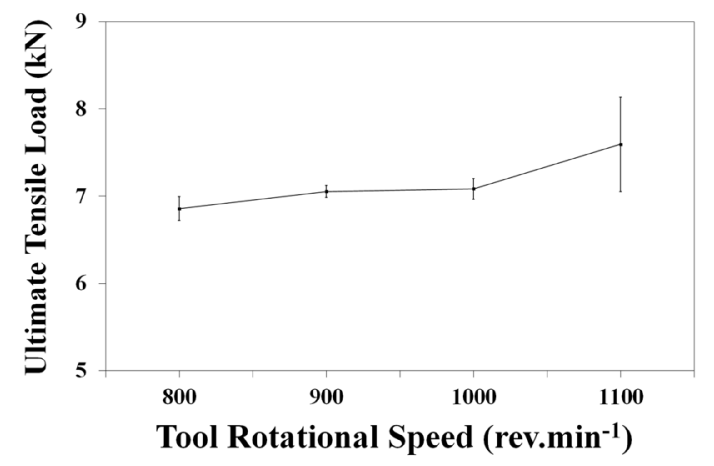

Figure 6. Fracture load versus tool rotational speed.

In joints produced at $1100 \mathrm{rpm}$, the hardness increase at the weld centre is not so apparent (Fig. 8), which is explained by the higher heat input and the consequent lower strain rate as described by Gerlich et al. ${ }^{18}$. Some hardness peaks are present and may be related to intermetallic compounds (IMC), as already reported by Shojaeefard et al. ${ }^{13}$.

According to Marya et al. ${ }^{26}$, welds produced with high heat input tend to show greater amounts of IMC which can reduce the shear strength of the joints. 


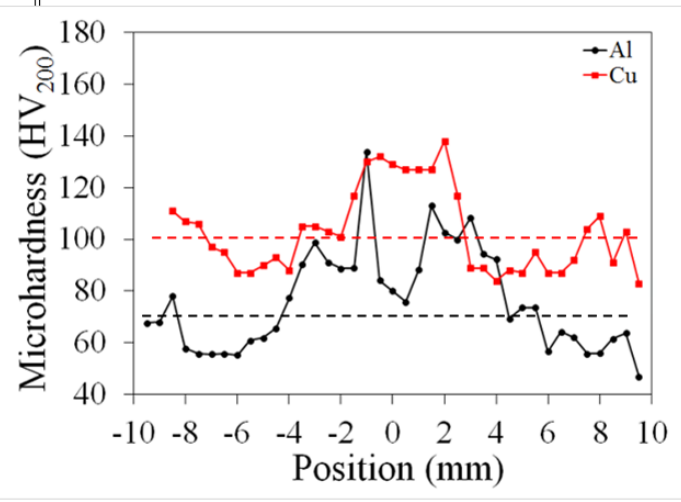

(a)

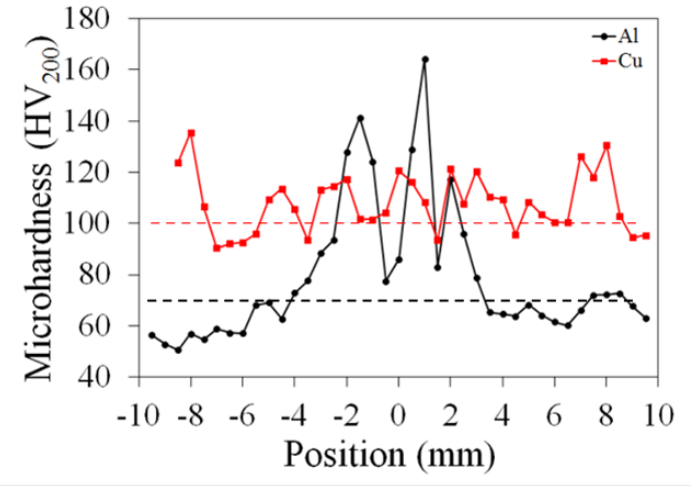

(b)

Figure 7. Microhardness profiles in cross section for WD 800/10 at (a) IS and (b) FS positions.

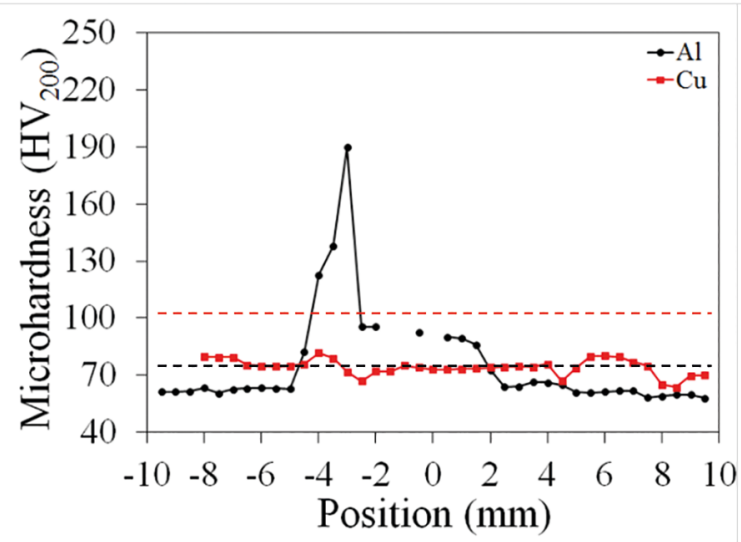

(a)

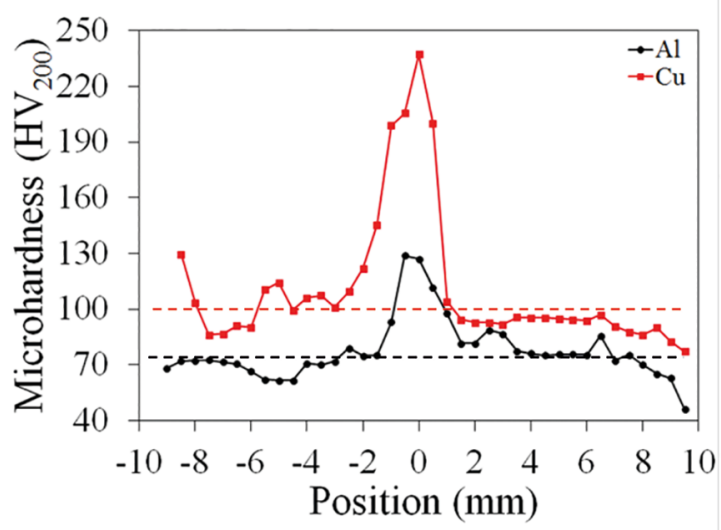

(b)

Figure 8. Microhardness profiles in cross section for WD 1100/10: (a) at IS (b) at FS positions.

\subsection{Microstructure}

A micrograph of the stir zone for WD 1000/10 is shown in Fig. 9. According to Abdollah-Zadeh et al. ${ }^{27}$, the dark grey zones correspond to regions where more copper was introduced into the aluminium and is associated with the presence of IMC.

Depending on the welding parameters, defects may be present in the microstructure. Klobcar et al. ${ }^{28}$, after testing a vast variety of FSW process parameters in aluminium alloy joints, observed that welds produced with 800 or 900 rpm presented defects such as tunnelling, also known as a wormhole defect.

Fig. 10a shows the macrograph of the cross section for WD 900/10 where a void can be seen. Fig. 10b for WD 800/10, shows that the voids propagate longitudinally along the weld. Dehghani et al. ${ }^{29}$ showed that increasing downward forging force by using threaded pin or increasing the plunge depth, can reduce or even eliminate the tunnel defect.

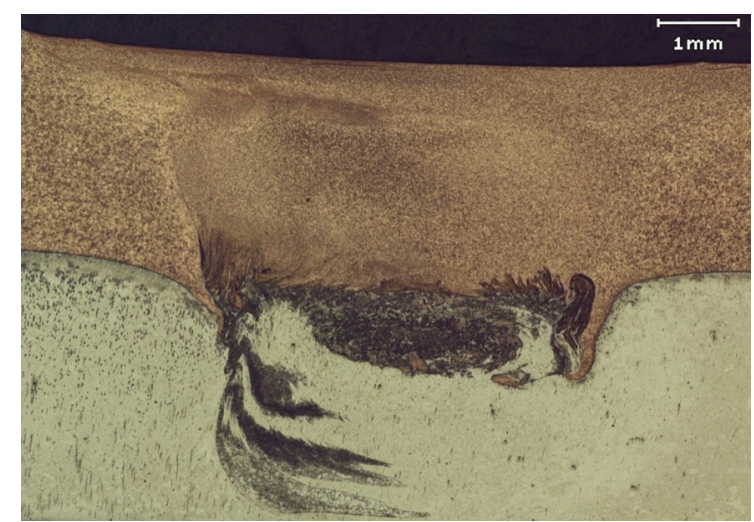

Figure 9. Copper-aluminium interface on a lap joint welded at WD 1000/10.

A feature commonly observed in FSW is known as stir bands or onion rings as shown in Fig. 11. According to Chen et al. ${ }^{30}$, the presence of stir bands is associated with lack of defects and high strength joints, as in the case of the present work. 


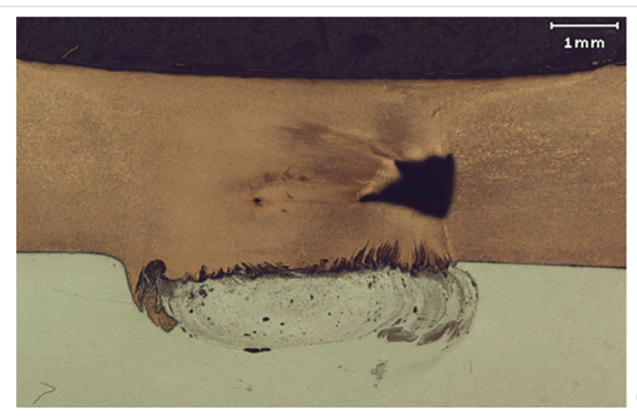

(a)

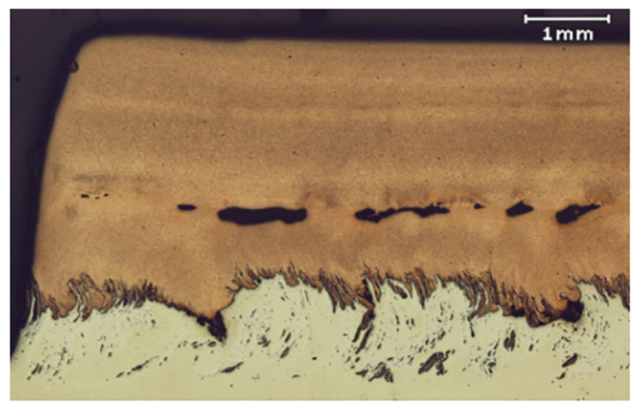

Figure 10. Micrograph showing the worm hole defect: (a) transversal section (WD 900/10) and (b) longitudinal section (800/10).

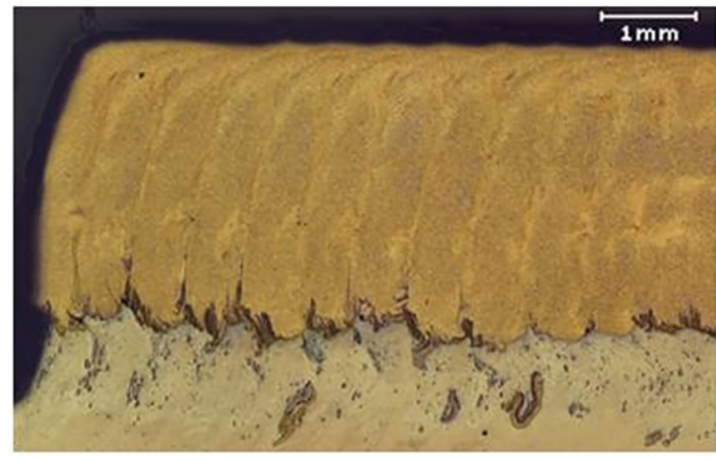

(a) WD $1000 / 10$

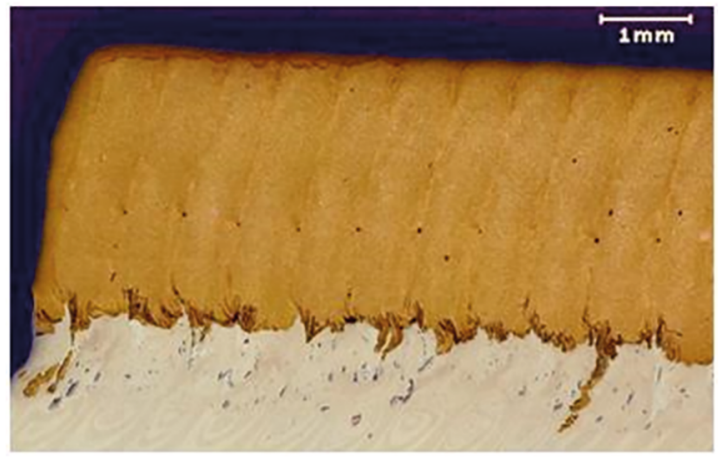

(b) WD $1100 / 10$

Figure 11. Stir bands in samples produced with high energy input.

Chen et al. ${ }^{30}$ state that the geometrical parameters of the tool, tilt angle, forging force and screw pitch contribute to many types of welding flaws. However, Khan et al. ${ }^{31}$ reported that tunnelling is not as deleterious to joint strength as a kissing bond that is a defect associated with insufficient frictional force and heat. In the present work, tunnelling was eliminated by increasing the heat input.

Special attention to plunge depth is mandatory in obtaining sound joints. If it is too shallow, it causes an inadequate material flow and lack of bonding between dissimilar material, which results in the formation of tunnelling defects and kissing bonds. However, if it is too deep, it causes over heating which leads to the generation of large amounts of IMC. Yilbas et al. ${ }^{32}$ report that small amount of intermetallic phases improve the tensile strength of the $\mathrm{Al}-\mathrm{Cu}$ welds, while a large amount results in poor strength.

In the present work, the presence of IMC was evident in welds produced at $1100 \mathrm{rpm}$, revealed by the peaks in the hardness profiles in Fig. 8 and also, in the high dispersion of shear strength observed in Fig. 6.

The joints produced at $800 \mathrm{rpm}$ presented a larger size of stir zone and a small amount of IMC, thus the more uniform hardness profile shown in Fig. 7. However, the samples showed the presence of flaws.
We suppose that the heat input from WD 1000/10 was adequate to keep the level of IMCs under control and avoid weld defects, thus the low dispersion in joint strength. Therefore, a joint efficiency of $85 \%$ was reached.

\subsection{Fracture mechanism}

For all the shear tensile tests reported in Fig. 6, fractures occurred in the aluminium sheet. The welded samples presented the same fracture pattern, as shown in Fig. 12 (a). The stress concentration at the beginning of the weld seam, in addition to the lower strength of the aluminium alloy, causes the fracture to take place in the aluminium sheet. A detail of the fracture is shown in Fig. 12 (b).

The fracture of the welded joints was governed by tension overload of the aluminium sheet. Fig. 13 shows an SEM image of the fracture surface, where it is possible to see the presence of equiaxed dimples, a typical failure caused by tension overload.

For the welding parameters studied in this works, the fracture mechanism of the joints was not associated with features of the weld. This explains the small difference of the shear tensile test results as shown in Fig. 6. However, the different welding parameters do affect the weld zones and IMC distribution, which have some effect on the joint strength. 


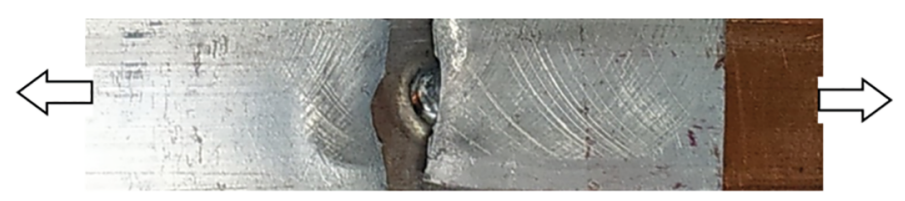

(a)

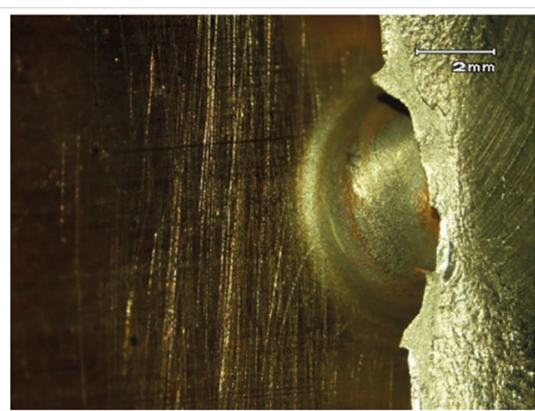

(b)

Figure 12. Fracture mechanisms: (a) overview of joint failure and (b) detail of aluminium sheet.

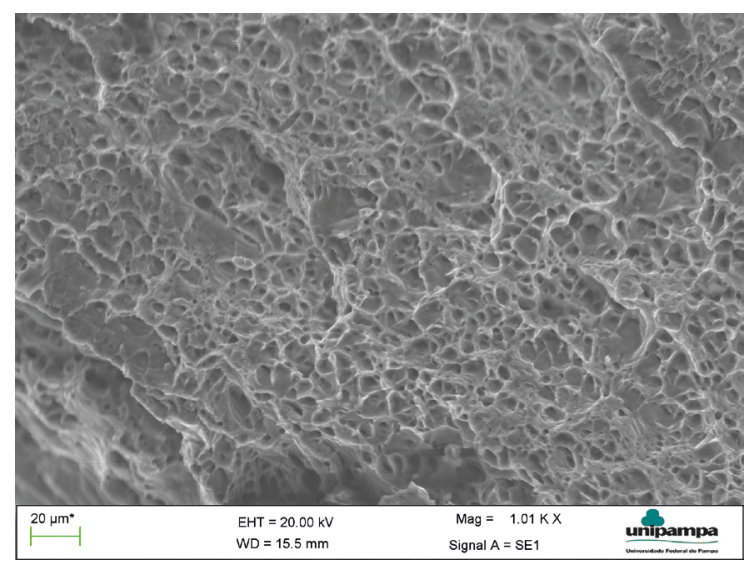

Figure 13. SEM image of the fracture surface showing the presence of equiaxed dimples.

\section{Conclusions}

The general characteristics of dissimilar $3.25 \mathrm{~mm} \mathrm{Al-Cu}$ lap joints welded by FSW were investigated. Analysis of the experimental data allowed the following conclusions:

- Stir bands, also known as onion rings, were associated with lack of defects and high strength joints.

- The increase of tool rotational speed increased the weld hardness.

- Welds produced with the $\omega / v$ rate of 26.7 rev. $\mathrm{mm}^{-1}$ resulted in inadequate mixture of material, surface defects and low strength.

- Welds produced with the $\omega / v$ rate of 200 rev. $\mathrm{mm}^{-1}$ or 500 rev. $\mathrm{mm}^{-1}$ resulted in melting of base materials and material leaking (500 rev. $\mathrm{mm}^{-1}$ ).

- Visually sound joints were produced with the $\omega / v$ rate between 80 rev. $\mathrm{mm}^{-1}$ to 110 rev. $\mathrm{mm}^{-1}$ which resulted in tensile strengths varying from 76 to $85 \%$ of the original resistance of the aluminium.

- In the rage of 80 rev. $\mathrm{mm}^{-1}$ to 110 rev. $\mathrm{mm}^{-1}$ the fracture was governed by tension overload of the aluminium sheet. In this condition, the presence of tunnelling defect had small influence on the maximum shear load.
- The feasibility of using copper on top for dissimilar Al-Cu FSW was demonstrated.

\section{Acknowledgements}

The authors would like to express their gratitude to CAPES, CNPq as well as FAPERGS for financial support of the project.

\section{References}

1. Firouzdor V, Kou S. Al-to-Cu Friction Stir Lap Welding. Metallurgical and Materials Transactions A . 2012;43(1):303-315.

2. Mai TA, Spowage AC. Characterisation of dissimilar joints in laser welding of steel-kovar, copper-steel and copper-aluminum. Materials Science and Engineering: A. 2004;374(1-2):224-233.

3. Rao KP, Ram GDJ, Stucker BE. Effect of friction stir processing on corrosion resistance of aluminum-copper alloy gas tungsten arc welds. Materials \& Design. 2010;31(3):1576-1580.

4. Xue P, Xiao BL, Wang D, Ma ZY. Achieving high property friction stir welded aluminum/copper lap joint at low heat input. Science and Technology of Welding and Joining. 2011;16(8):657-661.

5. Xue P, Xiao BL, Ni DR, Ma ZY. Enhance mechanical properties of friction stir welded dissimilar Al-Cu joint by intermetallic compounds. Materials Science and Engineering: A 2010;527(2122):5723-5727.

6. Ericsson M, Sandström R. Influence of welding speed on the fatigue of friction stir welds, and comparison with MIG and TIG. International Journal of Fatigue. 2003;25(12):1379-1387.

7. Vilaça P, Quintino L, dos Santos JF. iSTIR-Analytical thermal model for friction stir welding. Journal of Materials Processing Technology. 2005;169(3):452-465.

8. Bisadi H, Tavakoli A, Tour Sangsaraki M, Tour Sangsaraki K. The influences of rotational and welding speed on microstructures and mechanical properties of friction stir welded Al5083 and commercially pure copper sheets lap joints. Materials \& Design . 2013;43:80-88.

9. Ouyang J, Yarrapareddy E, Kovacevic R. Microstructural evolution in friction stir welded 6061 aluminum alloy (T6temper condition) to copper. Journal of Materials Processing Technology. 2006;172(1):110-122. 
10. Carlone P, Astarita A, Palazzo GS, Paradiso V, Squillace A. Microstructural aspects in Al-Cu dissimilar joining by FSW. International Journal of Advanced Manufacturing Technology. 2015;79(5-8):1109-1116.

11. Akbari M, Behnagh RA, Dadvand A. Effect of materials position on friction stir lap welding of Al to $\mathrm{Cu}$. Science and Technology of Welding and Joining. 2012;17(7):581-588.

12. Galvão I, Oliveira JC, Loureiro A, Rodrigues DM. Formation and distribution of brittle structures in friction stir welding of aluminium and copper: Influence of shoulder geometry. Intermetallics. 2012;22:122-128.

13. Shojaeefard MH, Khalkhali A, Akbari M, Tahani M. Application of Taguchi optimization technique in determining aluminum to brass friction stir welding parameters. Materials \& Design (1980-2015). 2013;52:587-592.

14. Mehta KP, Badheka VJ. Hybrid approaches of assisted heating and cooling for friction stir welding copper to aluminum joints. Journal of Materials Processing Technology. 2017;239:336-345.

15. Mehta KP, Badheka VJ. A Review on Dissimilar Friction Stir Welding of Copper to Aluminum: Process, Properties and Variants. Materials and Manufacturing Processes. 2016;31(3):233-254.

16. Schneider J, Beshears R, Nunes AC Jr. Interfacial sticking and slipping in friction stir welding process. Materials Science and Engineering: A. 2006;435-436:297-304.

17. Liechty BC, Webb BW. Modeling the frictional boundary condition in friction stir welding. International Journal of Machine Tools and Manufacture. 2008;48(12-13):1474-1485.

18. Gerlich A, Avramovic-Cingara G, North TH. Stir zone microstructure and strain rate during Al 7075-T6 friction stir spot welding. Metallurgical and Materials Transactions A. 2006;37(9):2773-2786.

19. Tier MD, Rosendo TS, dos Santos JF, Huber N, Mazzaferro JA, Mazzaferro CP, et al. The influence of refill FSSW parameters on the microstructure and shear strength of 5042 aluminium welds. Journal of Materials Processing Technology. 2013;213(6):9971005.

20. Rodrigues DM, Leitão C, Louro R, Gouveia H, Loureiro A. High speed friction stir welding of aluminium alloys. Science and Technology of Welding and Joining. 2010;15(8):676-681.

21. Shen Z, Chen Y, Hou JSC, Yang X, Gerlich AP. Influence of processing parameters on microstructure and mechanical performance of refill friction stir spot welded 7075-T6 aluminium alloy. Science and Technology of Welding and Joining. 2015;20(1):48-57.
22. Tan CW, Jiang ZG, Li LQ, Chen YB, Chen XY. Microstructural evolution and mechanical properties of dissimilar $\mathrm{Al}-\mathrm{Cu}$ joints produced by friction stir welding. Materials \& Design. 2013;51:466-473.

23. Muthu MFX, Jayabalan V. Tool travel speed effects on the microstructure of friction stir welded aluminum-copper joints. Journal of Materials Processing Technology. 2015;217:105-113.

24. Avettand-Fenoël MN, Tailard R, Ji G, Goran D. Multiscale Study of Interfacial Intermetallic Compounds in a Dissimilar Al 6082/Cu Friction-Stir Weld. Metallurgical and Materials Transactions A. 2012;43(12):4655-4666.

25. Kahl S, Osikowicz W. Composite Aluminum-Cooper Sheet Material by Friction Stir Welding and Cold Rolling. Journal of Materials Engineering and Performance. 2013;22(8):21762184.

26. Marya M, Marya S. Interfacial microstructures and temperatures in aluminium-copper electromagnetic pulse welds. Science and Technology of Welding and Joining. 2004;9(6):541-547.

27. Abdollah-Zadeh A, Saeid T, Sazgari B. Microstructural and mechanical properties of friction stir welded aluminum/copper lap joints. Journal of Alloys and Compounds. 2008;460(12):535-538

28. Klobčar D, Kosec L, Pepelnjak T, Tušek J. Microstructure and mechanical properties of friction stir welded $\mathrm{AlM}_{\mathrm{g} 4.5} \mathrm{Mn}$ alloy. Engineering Review. 2012;32(2):104-110.

29. Dehghani M, Amadeh A, Akbari Mousavi SAA. Investigations on the effects of friction stir welding parameters on intermetallic and defect formation in joining aluminum alloy to mild steel. Materials \& Design. 2013;49:433-441.

30. Chen HB, Yan K, Lin T, Chen SB, Jiang CY, Zhao Y. The investigation of typical welding defects for 5456 aluminum alloy friction stir welds. Materials Science and Engineering: A. 2006;433(1-2):64-69.

31. Khan NZ, Siddiquee AN, Khan ZA, Shihab SK. Investigations on tunneling and kissing bond defects in FSW joints for dissimilar aluminum alloys. Journal of Alloys and Compounds. 2015;648:360-367.

32. Yilbaș BS, Sahin AZ, Kahraman N, Al-Garni AZ. Friction welding of steel-Al and Al-Cu materials. Journal of Materials Processing Technology. 1995;49(3-4):431-443. 